\title{
Hydrophobic Vancomycin Derivatives with Improved ADME Properties: Discovery of Telavancin (TD-6424)
}

\author{
Michael R. Leadbetter*, Stacy M. Adams, Bettina Bazzini, Paul R. Fatheree, Dane E. Karr, \\ Kevin M. Krause, Bernice M. T. Lam, Martin S. Linsell, Matthew B. Nodwell ${ }^{\dagger}$, John L. Pace ${ }^{\dagger \dagger}$, \\ Kelly Quast, Jeng-Pyng Shaw, Elizabeth Soriano, Sean G. Trapp, Jenny D. Villena, \\ Terry X. Wu, Burton G. Christensen and J. Kevin Judice ${ }^{\dagger \dagger}$
}

Theravance, Inc., 901 Gateway Blvd., South San Francisco, CA 94080, USA

(Received for publication December 19, 2003)

\begin{abstract}
Novel derivatives of $N$-decylaminoethylvancomycin (2), containing appended hydrophilic groups were synthesized and their antibacterial activity and ADME properties were evaluated. The compounds were prepared by reacting amines with the $C$-terminus $\left(\mathbf{C}\right.$-) of 2 using PyBOP $^{\mathbb{R}}$ mediated amide formation, or with the resorcinol-like ( $\mathbf{R}-)$ position of $\mathbf{2}$ using a Mannich aminomethylation reaction. These analogs retained the antibacterial activity of $\mathbf{2}$ against methicillin-resistant staphylococci and vancomycin-resistant enterococci. Compounds with a negatively charged auxiliary group also exhibited improved ADME properties relative to 2 . In particular, R-phosphonomethylaminomethyl derivative 21 displayed good in vitro antibacterial activity, high urinary recovery and low distribution to liver and kidney tissues. Based on these results, 21 was advanced into development as TD-6424, and is currently in human clinical trials. The generic name telavancin has recently been approved for compound $\mathbf{2 1}$.
\end{abstract}

The continuing emergence of multidrug-resistant Gram-positive pathogens such as methicillin-resistant Staphylococcus aureus (MRSA), penicillin-resistant Streptococcus pneumoniae (PRSP) and vancomycinresistant enterococci (VRE) presents an increasing challenge to the heath-care community and has intensified the search for new, more effective treatment options ${ }^{1)}$. Of particular concern are recent reports of $S$. aureus with intermediate $(\mathrm{VISA})^{2)}$ or high-level (VRSA) ${ }^{3)}$ resistance to vancomycin (1) and other glycopeptides. While some recently introduced agents such as linezolid ${ }^{4)}$ and quinupristin/dalfopristin ${ }^{5)}$ are effective against resistant organisms, they are not without limitations, including further resistance and side effects ${ }^{6 \sim 8)}$. Accordingly, there is still a need to discover new agents to treat serious Grampositive infections.
Over the past two decades, a number of groups have explored modifications to vancomycin and other glycopeptides. Through these efforts it has been established that adding hydrophobic substituents can restore antibacterial activity against VRE while retaining potency against $\mathrm{MRSA}^{9 \sim 12)}$. As part of our effort to discover new antibacterial agents, we prepared $\mathrm{N}$ decylaminoethylvancomycin (2) and found it to be active in vitro against staphylococci including MRSA and VISA, with MIC's equal to or better than vancomycin (Table 1). In addition, $\mathbf{2}$ was active against enterococci regardless of their susceptibility to the glycopeptides vancomycin or teicoplanin.

While the appended hydrophobic group can improve the in vitro antibacterial activity of vancomycin, it also can impart unfavorable absorption, distribution, metabolism

\footnotetext{
† Present address: Angiotech Pharmaceuticals, 1618 Station Street, Vancouver, B.C., Canada V6A 1B6.

${ }^{+\dagger}$ Present address: 906 Calvert Street, St. Michaels, MD 21663.

${ }^{+++}$Present address: Department of Medicinal Chemistry, Genentech, Inc., 1 DNA Way, South San Francisco, CA 94080.

* Corresponding author: mleadbetter@theravance.com
} 
and excretion (ADME) properties such as long elimination half life and high tissue accumulation ${ }^{9,10)}$. Indeed, 2 proved to be poorly excreted, and distributed to liver and kidney tissues in rats (see below, Table 3 ). We speculated that by adding a hydrophilic group to reduce the overall lipophilicity of $\mathbf{2}$, we could restore the favorable distribution properties of vancomycin, while retaining the activity against resistant organisms conferred by the hydrophobic group. Specifically, we hoped to reduce liver and kidney accumulation and increase urinary excretion while maintaining potent in vitro antibacterial activity and bactericidal properties. In this paper we report the synthesis, in vitro activity, and the distribution and excretion profiles of doubly-modified vancomycin

Fig. 1. Structure of vancomycin (1) and $\mathrm{N}$-decylaminoethylvancomycin (2).

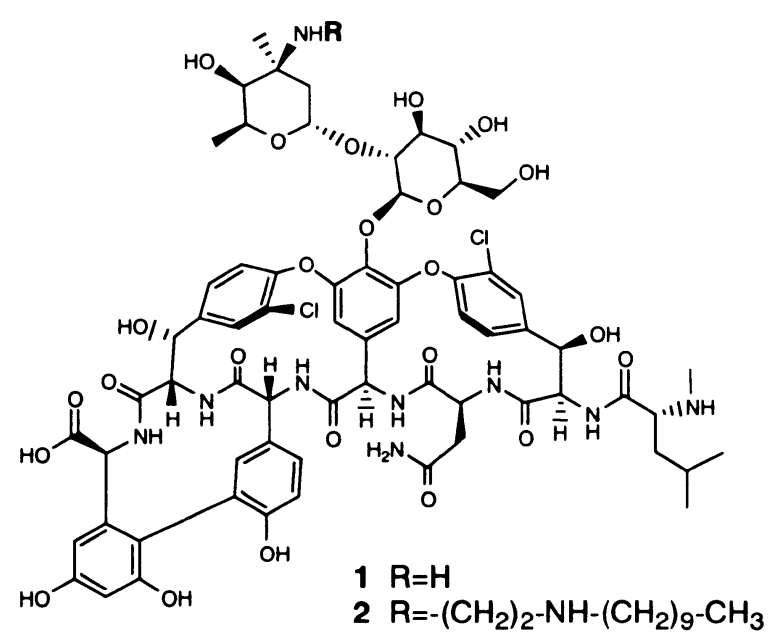

derivatives bearing both hydrophobic and hydrophilic groups.

\section{Chemistry}

Derivatives of $\mathbf{2}$ were prepared that included a hydrophilic group attached through either the carboxyl terminus (C-) or the resorcinol-like $4^{\prime}$ position (R-) of amino acid 7 (Figure 2). The hydrophilic substituents included positively and negatively charged groups as well as neutral hydroxylated alkyl groups. All compounds were purified by reversed phase HPLC (RP-HPLC) and characterized by ion-spray mass spectrometry. Mass spectrometry data is provided in Tables 2 and 4.

Compound 2 was synthesized by reductive alkylation of vancomycin with $N$-fluorenylmethoxycarbonyl- $N$-decyl aminoacetaldehyde as shown in Scheme $1^{13,14)}$. Imine formation was conducted under basic conditions and was followed by reduction with sodium cyanoborohydride and trifluoroacetic acid (TFA) to give 3 . Removal of the fluorenylmethoxycarbonyl (Fmoc) protecting group using piperidine afforded 2 . In the mass spectrum of $\mathbf{2}$ $(m / z=1633)$ we observed the fragment $m / z=1305$ which corresponds to loss of vancosamine plus decylaminoethyl. We did not observe the fragment $\mathrm{m} / \mathrm{z}=1488$ corresponding to loss of unsubstituted vancosamine. This confirmed that the reductive alkylation to make 3 had taken place on the vancosamine nitrogen rather than the $N$-methyl-D-leucine ${ }^{15 \text { ) }}$.

To prepare the $C$-terminal amides, we reacted intermediate 3 with the appropriate amine using benzotriazol-1-yloxytripyrrolidinophosphonium hexafluorophosphate $\left(\mathrm{PyBOP}^{\mathrm{k}}\right)$, 1-hydroxybenzotriazole $(\mathrm{HOBt})$ and $N, N$-diisopropylethylamine $\quad$ (DIEA) $^{16)} \quad($ Scheme 1$)$.

Table 1. In vitro antibacterial activity of $\mathbf{2}$ against Gram-positive pathogens compared to vancomycin, teicoplanin and linezolid.

\begin{tabular}{lcccc}
\hline & \multicolumn{3}{c}{ MIC $(\mu \mathrm{g} / \mathrm{mL})^{\mathrm{a}}$} \\
\cline { 2 - 5 } Organism & 2 & Vancomycin (1) & Teicoplanin & Linezolid \\
\hline Staphylococcus aureus ATCC 29213 & 0.5 & 1 & 1 & 4 \\
S. aureus ATCC 33591 & 0.7 & 1 & 2 & 2 \\
S. aureus HIP-5836 & 1 & 8 & 8 & 2 \\
Enterococcus faecalis ATCC 29212 & 1 & 2 & 0.5 & 4 \\
E. faecalis ATCC 51575 & 1 & $>256$ & 0.5 & 4 \\
E. faecalis ATCC 51575, & 8 & $>256$ & 32 & NT \\
E. faecalis MGH-019 & 3 & $>256$ & $>256$ & 2 \\
E. faecium ATCC 49624 & 0.5 & 0.3 & $>256$ & 4 \\
E. faecium CDC-019 & 8 & $>256$ & 4 \\
\hline
\end{tabular}

${ }^{\mathrm{a}}$ Minimum inhibitory concentration as determined by broth microdilution assays in vitro. ${ }^{\mathrm{b}}$ Methicillinresistant. ${ }^{c}$ Vancomycin-intermediate-resistant. ${ }^{\mathrm{d}}$ Vancomycin-resistant (VanB). ${ }^{\mathrm{e}}$ Incubated with vancomycin at $10 \mu \mathrm{g} / \mathrm{mL}$ to induce VanB resistance. ${ }^{\mathrm{f}}$ Not tested. ${ }^{\mathrm{g}}$ Vancomycin-resistant (VanA). 
Fig. 2. Structure of carboxy- (C-) and resorcinol- (R-) substituted $N$-decylaminoethylvancomycin analogs.

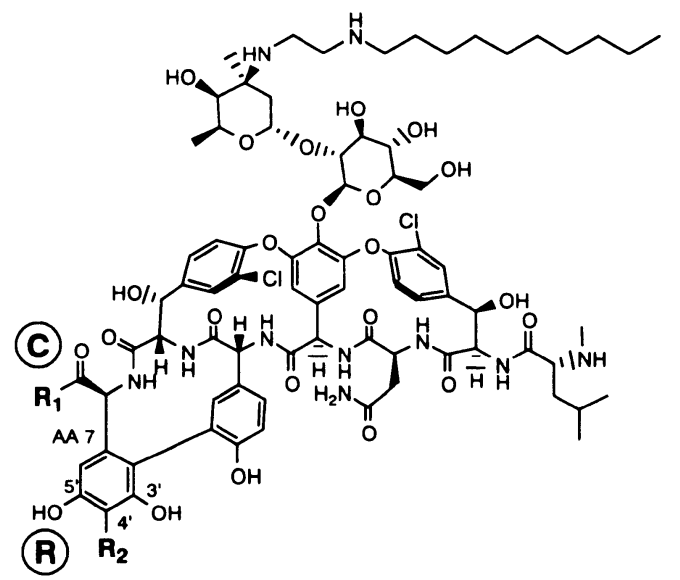

28

15

18

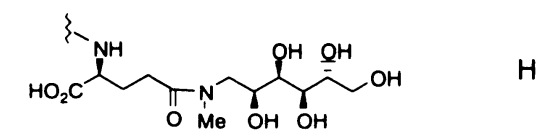

19

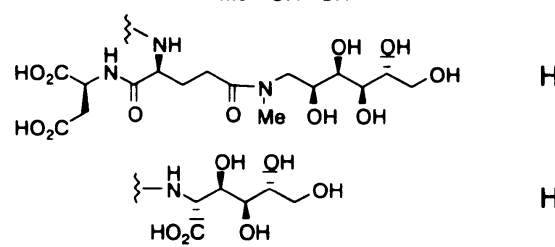

21

$\mathrm{OH}$

$\stackrel{\mathrm{H}_{2} \mathrm{C} .}{\mathrm{H}} \widehat{\sim} \mathrm{PO}_{3} \mathrm{H}_{2}$

22

$\mathrm{OH}$

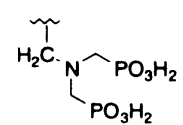

23

$\mathrm{OH}$

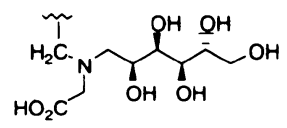

24

$\mathrm{OH}$

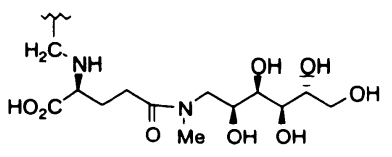

25

$$
\overbrace{\mathrm{HO}_{2} \overline{\mathrm{C}}}^{\sim \mathrm{C}-\mathrm{ONN}} \underbrace{\mathrm{QH}}_{\mathrm{OH}} \mathrm{OH}
$$


Scheme 1. Synthesis of $\mathbf{2}$ and $\mathbf{C}$-terminal amides.

1

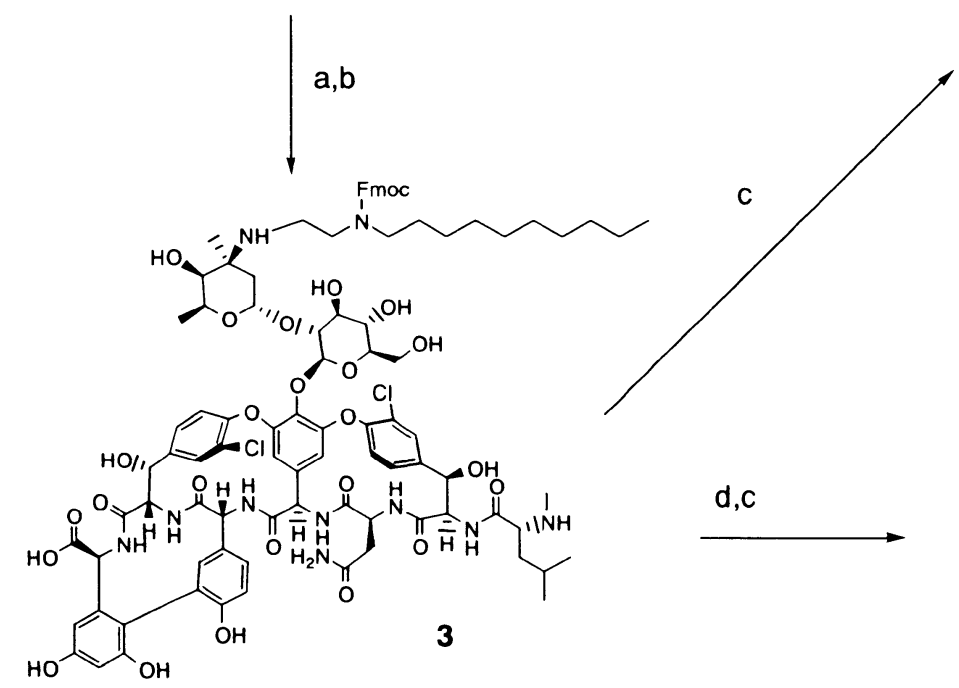

2

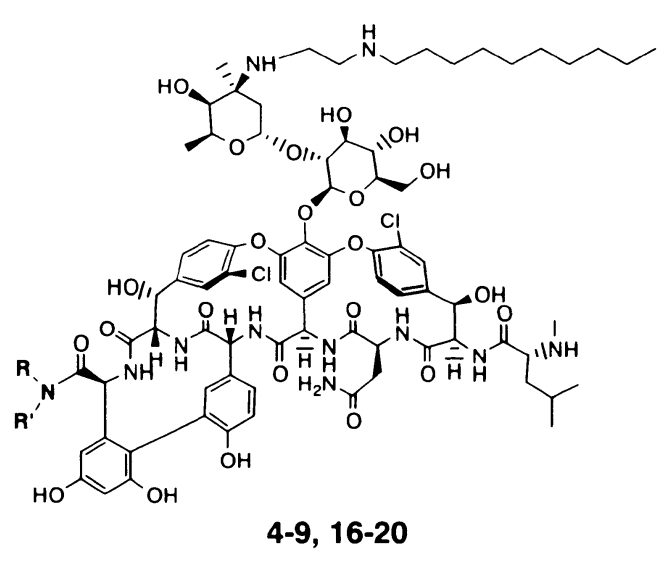

Reagents: (a) $N$-Fluorenylmethoxycarbonyl- $N$-decylaminoacetaldehyde, $i \mathrm{Pr}_{2} \mathrm{NEt}$, DMF; (b) $\mathrm{NaCNBH}_{3}, \mathrm{MeOH}$, TFA; (c) piperidine, DMF; (d) RR'NH, PyBOP $^{\circledast}$, HOBt, DMF.

Scheme 2. Synthesis of $\mathbf{R}$-substituted compounds and $\mathbf{1 5}$.

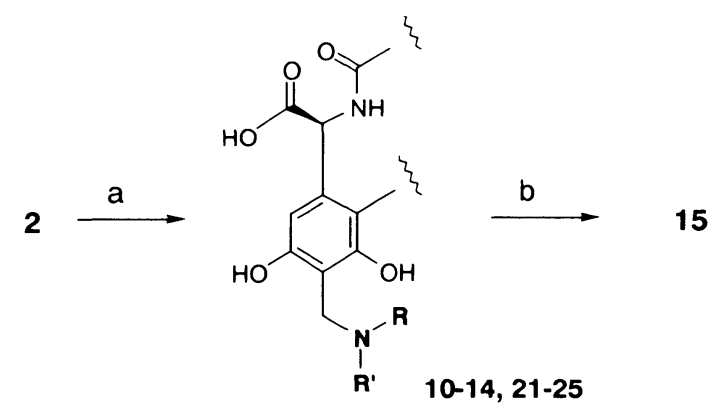

Reagents: (a) Formalin, RR'NH, $i-\mathrm{Pr}_{2} \mathrm{NEt}, \mathrm{CH}_{3} \mathrm{CN}, \mathrm{H}_{2} \mathrm{O}$; (b) D-glucosamine, PyBOP ${ }^{\circledR}$, $\mathrm{HOBt}$, DMF.

Subsequent deprotection with piperidine yielded compounds $\mathbf{4} \sim \mathbf{9}$ and $\mathbf{1 6} \sim \mathbf{2 0}$.

The R-substituted compounds were prepared through Mannich aminomethylation of $\mathbf{2}$, in a manner similar to that described by PAVLOV et al. for eremomycin ${ }^{12)}$. Compound $\mathbf{2}$, formalin and the desired amine were reacted under basic conditions to afford compounds $10 \sim 14$ and $21 \sim 25$ as depicted in Scheme 2. By limiting the amount of formaldehyde used, we were able to suppress side reactions $^{17)}$ as well as over-alkylation. To synthesize $\mathbf{1 5}$, with substituents at both $\mathbf{C}$ - and $\mathbf{R}$-positions, compound $\mathbf{1 0}$ was reacted with D-glucosamine using $\mathrm{PyBOP}^{\mathrm{R}}$ and $\mathrm{HOBt}$.

In order to confirm the point of attachment of the aminomethyl appendage of the $\mathbf{R}$-substituted compounds, a series of NMR experiments was performed on 21 . In the proton spectrum of $\mathbf{2 1}$, the resonance corresponding to the proton attached to the $4^{\prime}$ position of amino acid 7 was not observed. In addition, cross-peaks were observed in the 
Scheme 3. Synthesis of substituted glutamic acid intermediates.

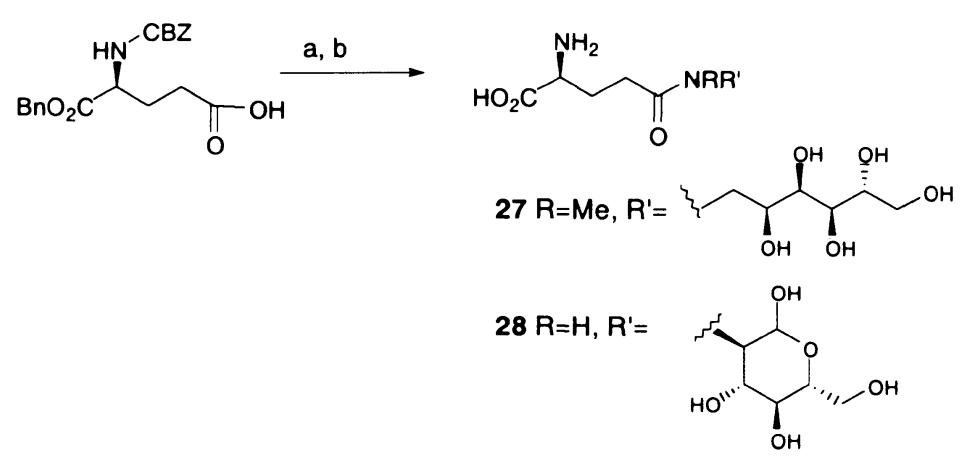

Reagents: (a) RR'NH, PyBOP ${ }^{\circledast}, \mathrm{HOBt}, i \mathrm{Pr}_{2} \mathrm{NEt}$, DMF. (b) $\mathrm{H}_{2} \mathrm{Pd} / \mathrm{C}, \mathrm{MeOH}$.

Scheme 4. Synthesis of $N$-carboxymethyl-D-glucamine.<smiles>CC(C)(C)C(=O)OCC(=O)O</smiles>

Reagents: (a) $\mathrm{NaCNBH}_{3}$, pH 7.0 phosphate buffer, DMF. (b) $\mathrm{NaOH}, \mathrm{MeOH}, \mathrm{DMF}$.

HMBC spectrum between the $-\mathrm{CH}_{2}-\mathrm{NHR}$ protons of the phosphonic acid appendage and the $3^{\prime}, 4^{\prime}$ and $5^{\prime}$ carbons, which confirmed the $4^{\prime}$ position as the point of attachment $^{12)}$.

Amines that were not commercially available were prepared as outlined in Schemes 3 and $4 . \mathrm{N}$ Benzyloxycarbonyl-O-benzyl-L-glutamic acid was treated with the appropriate aminosugar and $\mathrm{PyBOP}^{\mathrm{R}}$ and $\mathrm{HOBt}$ to form the amide. The protecting groups were removed by catalytic hydrogenation to provide the amino acids 27 and 28. The fluorenylmethyl ester of glycine was reductively alkylated with D-glucose using sodium cyanoborohydride in water and $\mathrm{DMF}$ at $\mathrm{pH} 7^{18)}$. Subsequent deprotection yielded the amino acid 29.

\section{Results and Discussion}

We examined a set of compounds $(\mathbf{4} \sim \mathbf{1 5})$ with negatively charged, positively charged and neutral hydrophilic groups appended to $\mathbf{2}$ in order to assess the effect on antibacterial activity and distribution. Minimum inhibitory concentrations (MIC) for these compounds against a panel of staphylococci and enterococci including MRSA and VRE are presented in Table 2, along with data for vancomycin and 2 . Overall, the substituents had a modest effect on in vitro potency. Several compounds displayed lower MIC values than $\mathbf{2}$ against staphylococci, but no doubly substituted compound showed a significant increase in potency against VanA VRE. The most potent compound was $\mathbf{8}$, which bears a negatively charged $\beta$ alanine at the $\mathbf{C}$ position. The MIC values for $\mathbf{8}$ were 3- to greater than 10-fold lower than $\mathbf{2}$ against staphylococci, and was equipotent with 2 against VanA VRE. Compounds with a basic nitrogen in the appended group $(4,14)$ were less potent than 2 against both staphylococci and VanA VRE.

We selected compounds from this series to determine the effects that various substituents had on distribution and excretion. Specifically, we chose to explore compounds of varying net charge in a single-dose ADME study in rats using a dosage of $10 \mathrm{mg} / \mathrm{kg}$. The tissue distribution data determined 24 hours after dosing is shown in Table 3. The 
Table 2. Analytical and antibacterial properties of hydrophilic $\mathbf{C}$ and $\mathbf{R}$ derivitives $\mathbf{4} \sim \mathbf{1 5}$, vancomycin and teicoplanin.

\begin{tabular}{|c|c|c|c|c|c|c|c|}
\hline \multirow[b]{2}{*}{ Compound } & \multicolumn{2}{|c|}{ Ion Spray MS } & \multicolumn{5}{|c|}{ MIC $(\mu \mathrm{g} / \mathrm{mL})^{\mathrm{c}}$} \\
\hline & $\begin{array}{c}m / z \\
\text { Calc'd }^{a} \\
\end{array}$ & $\begin{array}{c}m / z \\
\text { Obs'd }\end{array}$ & $\begin{array}{c}\text { Staphylococcus } \\
\text { aureus } \\
\text { ATCC } 13709\end{array}$ & 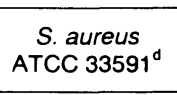 & $\begin{array}{c}\text { Enterococcus } \\
\text { faecalis } \\
\text { ATCC } 51575^{\circ} \\
\end{array}$ & $\begin{array}{l}\text { E. faecium } \\
\text { KPB-01 }\end{array}$ & $\begin{array}{l}\text { E. faecalis } \\
\mathrm{MGH}-01^{\prime}\end{array}$ \\
\hline Vancomycin (1) & -- & -- & 0.7 & 1 & $>50$ & $>50$ & $>50$ \\
\hline Teicoplanin & -- & -- & 0.8 & 2 & 0.5 & $>50$ & $>50$ \\
\hline 2 & 1633.6 & 1632.7 & 0.5 & 0.7 & 1 & 2.5 & 2.8 \\
\hline 4 & 1717.8 & 1718.2 & 1.2 & 1.5 & 1 & 3.1 & 3.9 \\
\hline 5 & 1720.7 & 1720.5 & 0.8 & 1.2 & 4.7 & 2.3 & 3.1 \\
\hline 6 & 1794.8 & 1794.9 & 0.5 & 0.8 & 0.8 & 2.6 & 3.5 \\
\hline 7 & 1810.8 & 1810.8 & 0.1 & 0.2 & 1.6 & 3.1 & 3.1 \\
\hline 8 & 1704.7 & 1705.2 & $<0.05$ & 0.2 & 0.1 & 3.1 & 2.3 \\
\hline 9 & 1748.7 & 1747.4 & 0.3 & 0.5 & 1.1 & 6.7 & 5.3 \\
\hline 10 & 1840.8 & 1840.4 & 1.5 & 1.2 & 2 & 4.2 & 6.8 \\
\hline 11 & 1734.7 & 1735.8 & 0.1 & 0.3 & 0.8 & 6.3 & 4.7 \\
\hline 12 & 1778.7 & 1779.0 & 0.2 & 0.5 & 1 & 13 & 9.4 \\
\hline 13 & 1750.8 & 1750.5 & 0.1 & 3.3 & 0.8 & 4.7 & 3.1 \\
\hline 14 & 1747.8 & 1747.8 & 3.1 & 3.1 & 3.1 & 6.3 & 6.3 \\
\hline 15 & 2002.0 & 2001.6 & 0.2 & 0.1 & 0.3 & 1.6 & 3.1 \\
\hline
\end{tabular}

${ }^{\mathrm{a}}$ Calculated mass-to-charge ratios for singly charged parent ions $\left(\mathrm{M}+\mathrm{H}^{+}\right) .{ }^{b}$ Observed mass-to-charge ratios for singly charged parent ions $\left(\mathrm{M}+\mathrm{H}^{+}\right)$.

${ }^{\mathrm{c}}$ Minimum inhibitory concentrations in micrograms per milliliter as determined by microdilution broth assays in vitro. ${ }^{\mathrm{d}} \mathrm{Methicillin}$-resistant.

${ }^{e}$ Vancomycin-resistant (VanB). ${ }^{\text {f }}$ Vancomycin-resistant (VanA).

Table 3. Single-dose distribution study in the rat (i.v., $10 \mathrm{mg} / \mathrm{kg}$ ).

\begin{tabular}{|c|c|c|c|c|c|}
\hline \multirow[t]{2}{*}{ Compound } & \multirow[t]{2}{*}{ Substitution $^{\mathrm{a}}$} & \multirow[t]{2}{*}{ Net Charge $^{b}$} & \multicolumn{3}{|c|}{${\text { Tissue Distribution }(\%)^{c}}^{c}$} \\
\hline & & & urine & liver & kidney \\
\hline vancomycin & -- & +1 & 65 & $<1$ & $<1$ \\
\hline 9 & C & 0 & 67 & 11 & 6 \\
\hline 2 & -- & +1 & 16 & 16 & 6 \\
\hline 6 & C & +2 & 23 & 30 & 9 \\
\hline 10 & $\mathbf{R}$ & +2 & 23 & 10 & 3 \\
\hline 4 & C & +3 & $<1$ & 28 & 6 \\
\hline 15 & $\mathbf{C}+\mathbf{R}$ & +3 & 5 & 23 & 16 \\
\hline
\end{tabular}

data suggested that the net charge of these vancomycin derivatives had a substantial impact on distribution. Notably, the compound predicted to have zero net charge at physiological $\mathrm{pH}$ had the highest urinary recovery (9), while compounds with the greatest net positive charge (4 and 15) showed very low urinary clearance and high concentrations in liver or kidney tissues.

While none of these compounds proved suitable for advancement, we were encouraged that compound $\mathbf{9}$ was excreted in the urine much more efficiently than was 2 . In this assay, the urinary recovery of compound 9 was equivalent to that of vancomycin (1). To follow up on the 
Table 4. Analytical and antibacterial properties of negatively charged $\mathbf{C}$ and $\mathbf{R}$ derivatives $\mathbf{1 6} \sim \mathbf{2 5}$, vancomycin and tiecoplanin.

\begin{tabular}{|c|c|c|c|c|c|c|c|}
\hline \multirow[b]{2}{*}{ AMI } & \multicolumn{2}{|c|}{ Ion Spray MS } & \multicolumn{5}{|c|}{$\mathrm{MIC}(\mu \mathrm{g} / \mathrm{mL})$} \\
\hline & $\begin{array}{c}m / z \\
\text { Calc'd }^{a}\end{array}$ & $\begin{array}{c}m / z \\
\text { Obs'd }\end{array}$ & $\begin{array}{c}\text { Staphylococcus } \\
\text { aureus } \\
\text { ATCC } 13709\end{array}$ & $\begin{array}{c}\text { S. aureus } \\
\text { ATCC } 33591^{\circ}\end{array}$ & $\begin{array}{l}\text { Enterococcus } \\
\text { faecalis } \\
\text { ATCC } 51575^{\ominus}\end{array}$ & $\begin{array}{l}\text { E. faecium } \\
\text { KPB-01 }\end{array}$ & $\begin{array}{l}\text { E. faecalis } \\
\text { MGH-01' }\end{array}$ \\
\hline Vancomycin & -. & -- & 0.7 & 1 & $>50$ & $>50$ & $>50$ \\
\hline Teicoplannin & -. & -- & 0.8 & 2 & 0.5 & $>50$ & $>50$ \\
\hline 2 & 1633.6 & 1632.7 & 0.5 & 0.7 & 1 & 2.5 & 2.8 \\
\hline 16 & 1726.6 & 1726.6 & 0.3 & 0.4 & 1.6 & 6.3 & 6.3 \\
\hline 17 & 1923.9 & 1823.8 & 0.5 & 0.4 & 1.2 & 6.3 & 4.7 \\
\hline 18 & 1939.9 & 1939.7 & 1.0 & 0.6 & 1.6 & 13 & 9.4 \\
\hline 19 & 2055.0 & 2054.7 & 1.2 & 0.8 & 1.6 & 13 & 13 \\
\hline 20 & 1810.8 & 1810.8 & 0.1 & 0.2 & 0.9 & 6.3 & 4.7 \\
\hline 21 & 1756.7 & 1756.6 & 0.6 & 0.8 & 1.6 & 6.3 & 9.4 \\
\hline 22 & 1850.7 & 1850.6 & 2.3 & 3.9 & 4.7 & 13 & 9.4 \\
\hline 23 & 1884.8 & 1884.7 & 1.2 & 0.8 & 1.6 & 6.3 & 6.3 \\
\hline 24 & 1970.0 & 1970.8 & 3.1 & 2.3 & 4.7 & 13 & 13 \\
\hline 25 & 1840.8 & 1840.8 & 0.4 & 0.8 & 1.2 & 9.3 & 6.3 \\
\hline
\end{tabular}

${ }^{\mathrm{a}}$ Calculated mass-to-charge ratios for singly charged parent ions $\left(\mathrm{M}+\mathrm{H}^{+}\right) .{ }^{b}$ Observed mass-to-charge ratios for singly charged parent ions $\left(\mathrm{M}+\mathrm{H}^{+}\right)$. ${ }^{\mathrm{c}}$ Minimum inhibitory concentrations in micrograms per milliliter as determined by microdilution broth assays in vitro. ${ }^{\mathrm{d}} \mathrm{Methicillin}$-resistant.

${ }^{\mathrm{e}}$ Vancomycin-resistant (VanB). ${ }^{\mathrm{f}}$ Vancomycin-resistant (VanA).

suggestion that decreasing net positive charge was critical to improving clearance and distribution properties, we prepared another set of analogs containing negatively charged groups at the $\mathbf{C}$ - or R-position (compounds 16 25)

As can be seen from Table 4, this set of compounds was also very active against staphylococci in vitro. The greatest increase in potency was seen with 20 which was 3- to 5fold more active against MSSA and MRSA than was 2 . Reduced potency was seen with the bisphosphonic acid derivative 22, and with glucamine glutamate 24, which displays 3 6 fold higher MIC values against staphylococci. Against VanA VRE, none of the substituted compounds was more active than $\mathbf{2}$ and most were at least slightly less potent.

We examined a subset of these compounds in an intravenous single-dose ADME study in rats at $50 \mathrm{mg} / \mathrm{kg}$ to determine whether the distribution and elimination properties had been improved relative to $\mathbf{2}$ by the addition of the negatively charged group. We chose $\mathbf{2 1}$, containing a phosphonic acid at the R-position ${ }^{19)}, \mathbf{1 8}$ and $\mathbf{2 4}$ which contained the same $N$-methyl-D-glucamine glutamate substituent at the C-position and the R-position, respectively.

The tissue distribution data measured at 24 hours after dosing are displayed in Table 5. In all cases there was a substantial increase in urinary clearance and decrease in liver and kidney distribution compared with 2 . Again, the data supported the observation that the addition of a negatively charged auxiliary hydrophilic group could increase the urinary excretion and decrease the liver and kidney distribution of a hydrophobic vancomycin derivative. Based on the results of this study, as well as its antibacterial activity, $\mathbf{2 1}$ was selected for further investigation.

To determine the effects of prolonged exposure to 21 on distribution and elimination, we undertook a multiple dose ADME study in the rat. Compound $\mathbf{2 1}$ was dosed for 7 days at $25 \mathrm{mg} / \mathrm{kg} /$ day. Efficient clearance was seen, with $58 \%$ of the last dose being recovered in the urine 24 hours after administration. Tissue accumulation was low, with $1 \%$ of the total dose detected in the liver and $0.2 \%$ of the total dose detected in the kidneys 24 hours after the last dose.

Further studies have shown that $\mathbf{2 1}$ has excellent 
Table 5. Single-dose distribution study in the rat (i.v., $50 \mathrm{mg} / \mathrm{kg}$ ).

\begin{tabular}{ccccc}
\hline Compound & Net Charge $^{\mathrm{a}}$ & \multicolumn{3}{c}{ Tissue distribution $(\%)^{\mathrm{b}}$} \\
& & urine & liver & kidney \\
\hline 2 & +1 & 12 & 16 & 13 \\
21 & 0 & 40 & 5 & 2 \\
18 & +1 & 58 & 6 & 3 \\
24 & +1 & 72 & 4 & 1 \\
\hline
\end{tabular}

\footnotetext{
${ }^{a}$ Estimated net charge at $\mathrm{pH} 7.5 .{ }^{b}$ Values are percentage of $50 \mathrm{mg} / \mathrm{kg}$ dose, 24 hours after dosing.
}

antibacterial activity against a range of clinical isolates including MSSA, MRSA and VISA and is rapidly bactericidal against these same organisms ${ }^{20)}$. In addition, we have reported that this favorable in vitro profile is expressed in vivo, where $\mathbf{2 1}$ was superior to nafcillin against MSSA and superior to vancomycin against MRSA in animal models ${ }^{21}$.

Based on its excellent antibacterial activity, both in vitro and in vivo, and favorable ADME properties, 21 was advanced into development as TD-6424, and is currently in human clinical trials. The generic name telavancin has recently been approved for compound $\mathbf{2 1}$.

\section{Experimental}

\section{General Methods}

Reagents and solvents were used as received from commercial suppliers and all reactions were carried out at room temperature and without rigorous exclusion of ambient atmosphere unless otherwise noted. Ion-spray mass spectra (IS-MS) were obtained on a PE Sciex API 150EX mass spectrometer operating in positive ion mode. Nuclear magnetic resonance (NMR) specta were recorded on a Varian XL-600 NMR spectrometer in DMSO- $d_{6}$ at $70^{\circ} \mathrm{C}$. Abbreviations for reagents: $\mathrm{Cbz}$ (benzyloxycarbonyl), Fmoc (fluorenylmethoxycarbonyl), DIEA $(N, N$ diisopropylethylamine).

\section{HPLC Methods}

Analytical: Reactions were monitored by analytical reversed-phase HPLC (RP-HPLC) with an HP1100 instrument using a $2.1 \mathrm{~mm} \times 50 \mathrm{~mm}, 3.5 \mu \mathrm{m} \mathrm{C} 14$ Zorbax Plus Bonus-RP column with UV detection at $214 \mathrm{~nm}$. For the analytical separations, a 0.5 minutes isocratic period was followed by a 4.5 minutes gradient of $2 \sim 90 \%$ acetonitrile in water with $0.1 \%$ TFA.

Preparative: Compounds were purified by preparative RP-HPLC on a Varian ProStar system using 2.5 or $5.0 \mathrm{~cm} \times 25 \mathrm{~cm}$ Rainin Dynamax columns and flow rates of 15 or $50 \mathrm{ml} /$ minute, respectively. Separations were accomplished with a gradient of $5 \sim 60 \%$ acetonitrile in water containing $0.1 \%$ TFA over 90 minutes.

$N^{\prime}$-Fluorenylmethoxycarbonyl- $N$-decylaminoethylvancomycin (3)

Vancomycin hydrochloride ( $12 \mathrm{~g}, 7.7 \mathrm{mmol}), \mathrm{N}$-Fmoc- $N$ decylaminoacetaldehyde $(3.2 \mathrm{~g}, \quad 7.6 \mathrm{mmol})$ and DIEA $(2.6 \mathrm{ml} 14.9 \mathrm{mmol})$ were stirred in DMF $(120 \mathrm{ml})$ for 90 minutes. Sodium cyanoborohydride $(1.4 \mathrm{~g}, 22 \mathrm{mmol})$ was added, followed by methanol $(120 \mathrm{ml})$ and TFA $(1.8 \mathrm{ml}$, $23 \mathrm{mmol}$ ). Stirring was continued for one hour, and the methanol was removed under reduced pressure. The crude product was precipitated by addition to ether $(600 \mathrm{ml})$, and the solid was collected on a Buchner funnel and dried under vacuum. The crude product was purified by column chromatography on $\mathrm{C} 18$ reverse phase silica gel, eluting with 10,20 and $30 \% \mathrm{ACN}$ in water containing $0.1 \%$ TFA, followed by $70 \% \mathrm{CH}_{3} \mathrm{CN}$ in water containing $0.1 \%$ TFA to elute the product. The fractions containing product were combined and lyophilized to give the TFA salt of $3(9 \mathrm{~g}$, $56 \%)$.

\section{$\mathrm{N}$-Decylaminoethylvancomycin (2)}

Compound $3(2.0 \mathrm{~g}, 1.0 \mathrm{mmol})$ was dissolved in DMF $(10 \mathrm{ml})$ and piperidine $(2.0 \mathrm{ml}, 20 \mathrm{mmol})$ was added. After stirring for 30 minutes, the crude deprotected product was precipitated by pouring into $\mathrm{CH}_{3} \mathrm{CN}(80 \mathrm{ml})$ and collected by centrifuge. The pellet was washed with ether $(80 \mathrm{ml})$, collected by centrifuge, and the solid was dried under 
vacuum. The crude product was purified by RP-HPLC to give the TFA salt of $2(1.0 \mathrm{~g}, 52 \%)$.

R-(Phosphonomethyl)aminomethyl- $N$-decylaminoethylvancomycin (21)

(Aminomethyl)phosphonic acid $(3.88 \mathrm{~g}, 35 \mathrm{mmol})$ and DIEA $(6.1 \mathrm{ml}, 35 \mathrm{mmol})$ were combined in water and stirred until homogenous. Acetonitrile $(50 \mathrm{ml})$ and formaldehyde ( $37 \%$ solution in water, $0.42 \mathrm{ml}, 5.6 \mathrm{mmol}$ ) were then added, followed by $3(10.0 \mathrm{~g}, 5.1 \mathrm{mmol})$ and DIEA $(6.1 \mathrm{ml}, 35 \mathrm{mmol})$. After approximately 18 hours, the solution was neutralized with $20 \%$ aqueous TFA, the acetonitrile was removed under reduced pressure, and the resulting suspension was lyophilized. The recovered solid was triturated with water $(100 \mathrm{ml})$, collected by filtration, dried under reduced pressure and purified by RP-HPLC to give $21(3.05 \mathrm{~g}, 27 \%)$.

\section{$N$-Decylaminoethylvancomycin, L-Aspartylamide (9)}

To a solution of $3(20 \mathrm{~g}, 10.4 \mathrm{mmol})$ and DIEA $(5.44 \mathrm{ml}$, $31.2 \mathrm{mmol})$ in DMF $(440 \mathrm{ml})$ were added sequentially HOBt $(1.47 \mathrm{~g}, 10.9 \mathrm{mmol})$, PyBOP $^{\mathrm{k}}(7.57 \mathrm{~g}, 14.6 \mathrm{mmol})$ and the TFA salt of the bis-fluorenylmethyl ester of Laspartic acid $(6.26 \mathrm{~g}, 10.4 \mathrm{mmol})$. After 1 hour, the crude product was precipitated by pouring the reaction mixture into $\mathrm{CH}_{3} \mathrm{CN}$ (4 liters), and the solid was collected by centrifuge. The supernatant was decanted and the pellet redissolved in DMF (440 ml). Piperidine ( $44 \mathrm{ml}, 44 \mathrm{mmol})$ was added, and the reaction was stirred for 1 hour. The reaction mixture was poured into ether (4 liters) to precipitate the crude deprotected product, which was collected on a Buchner funnel. The recovered solid was then triturated with $\mathrm{CH}_{3} \mathrm{CN}$ (4 liters), collected on a Buchner funnel, and dried under vacuum. The resulting offwhite solid was purified by RP-HPLC to give the TFA salt of $9(9.8 \mathrm{~g}, 45 \%)$.

\section{$N$ - $(\gamma$-L-Glutamyl)- $N$-methyl-D-glucamine (27)}

To a solution of $\mathrm{N}$-Cbz-O-benzyl-L-glutamic acid $(10.0 \mathrm{~g}$, $27 \mathrm{mmol})$ and $N$-methyl-D-glucamine $(5.3 \mathrm{~g}, 27 \mathrm{mmol})$ in DMF $(60 \mathrm{ml})$ was added HOBt $(4.1 \mathrm{~g}, 27 \mathrm{mml})$, PyBOP ${ }^{\mathrm{R}}$ $(15.4 \mathrm{~g}, 29 \mathrm{mmol})$ and DIEA $(7.0 \mathrm{ml}, 40 \mathrm{mmol})$. The solution was stirred for 1 hour, at which time it was poured in to water $(600 \mathrm{ml})$ containing $\mathrm{K}_{2} \mathrm{CO}_{3}(30 \mathrm{~g})$. The solution was extracted with ethyl acetate, and the organics were washed with $1 \mathrm{~N} \mathrm{HCl}$ in saturated $\mathrm{NaCl}$, and saturated $\mathrm{NaHCO}_{3}$. The organic layer was dried over $\mathrm{Na}_{2} \mathrm{SO}_{4}$, and concentrated under reduced pressure. The residual oil was dissolved in methanol $(100 \mathrm{ml})$ and $10 \% \mathrm{Pd} / \mathrm{C}(1.6 \mathrm{~g})$ was added under nitrogen. $4.0 \mathrm{~N} \mathrm{HCl}$ in dioxane $(10 \mathrm{ml}$,
$40 \mathrm{mmol}$ ) was added, and the reaction was stirred under one atmosphere of hydrogen for 3 hours. The mixture was filtered through Celite ${ }^{\mathbb{R}}$, which was washed with methanol. The filtrate was concentrated under reduced pressure to approximately $30 \mathrm{ml}$, and then added to $\mathrm{CH}_{3} \mathrm{CN}(300 \mathrm{ml})$. The precipitate was collected on a Buchner funnel and dried in vacuo to give the hydrochloride salt of $27(6.9 \mathrm{~g}$, $71 \%$ ) which was used without further purification.

$N$-Decylaminoethylvancomycin, Amide with $N$ - $(\gamma$-LGlutamyl)- $N$-methyl-D-glucamine (18)

Intermediate $3(1.8 \mathrm{~g}, 0.91 \mathrm{mmol}), \operatorname{PyBOP}^{\mathbb{R}}(0.52 \mathrm{~g}$, $1.0 \mathrm{mmol})$ and $\mathrm{HOBt}(0.15 \mathrm{~g}, 1.0 \mathrm{mmol})$ were dissolved in DMF $(12 \mathrm{ml})$, and $N$-methylmorpholine $(0.10 \mathrm{ml}$, $0.91 \mathrm{mmol}$ ) was added. The reaction was stirred for 20 minutes, at which time an additional portion of $\mathrm{N}$ methylmorpholine $(0.10 \mathrm{ml}, 0.91 \mathrm{mmol})$ was added. After 5 minutes, a solution of the amine hydrochloride $27(0.66 \mathrm{~g}$, $1.8 \mathrm{mmol})$ in DMF $(2.0 \mathrm{ml})$ was added, followed by another portion of $N$-methylmorpholine $(0.40 \mathrm{ml}, 3.6 \mathrm{mmol})$. The reaction mixture was stirred for 20 minutes, and then poured in to ether $(150 \mathrm{ml})$. The solid was collected on a Buchner funnel, washed with ether and dried under vacuum. The crude material was slurried in DMF $(30 \mathrm{ml})$, and piperidine $(6 \mathrm{ml}, 6 \mathrm{mmol})$ was added. The reaction was stirred for 20 minutes, at which time it was poured into ether $(150 \mathrm{ml})$. The solid was collected on a Buchner funnel, rinsed with ether and dried in vacuo. The crude deprotected product was purified by RP-HPLC to give $\mathbf{1 8}$ $(0.45 \mathrm{~g}, 22 \%)$.

R-[N-( $\gamma$-L-Glutamyl)- $N$-methyl-D-glucamino $]$ methyl$\mathrm{N}$-decylaminoethylvancomycin (24)

Amino acid $27(3.15 \mathrm{~g}, 8.8 \mathrm{mmol})$, intermediate 3 (1.8 g, $0.91 \mathrm{mmol})$ and DIEA $(2.9 \mathrm{ml}, 17 \mathrm{mmol})$ were dissolved in $\mathrm{CH}_{3} \mathrm{CN}(7.5 \mathrm{ml})$ and water $(7.5 \mathrm{ml})$, and $37 \%$ formaldehyde $(55 \mu \mathrm{l}, 0.73 \mathrm{mmol})$ was then added. After stirring for 4 hours, the $\mathrm{CH}_{3} \mathrm{CN}$ was removed under reduced pressure and the mixture was neutralized with TFA. The resulting thick slurry was dried under vacuum. The residue was dissolved in DMF $(9.6 \mathrm{ml})$ and piperidine $(1.2 \mathrm{ml}, 1.2 \mathrm{mmol})$ was added. The reaction mixture was stirred for 30 minutes at which time it was added to $\mathrm{CH}_{3} \mathrm{CN}(100 \mathrm{ml})$. The resulting solid was collected on a Buchner funnel, dried in vacuo and purified by RP-HPLC to give the TFA salt of $24(0.26 \mathrm{~g}$, $12 \%)$.

$\mathrm{N}$-Carboxymethyl-D-glucamine (29)

A solution of the fluorenylmethyl ester of glycine $(10.0 \mathrm{~g}$, $27.2 \mathrm{mmol})$ and D-glucose $(7.4 \mathrm{~g}, 41 \mathrm{mmole})$ in DMF 
$(70 \mathrm{ml})$ and $\mathrm{pH} 7.0$ phosphate buffer $(1.0 \mathrm{M}, 30 \mathrm{ml})$ was stirred for 30 minutes. Sodium cyanoborohydride $(1.7 \mathrm{~g}$, $27.2 \mathrm{mmol}$ ) was added, and the reaction stirred for 1.5 hours. The mixture was concentrated to dryness under reduced pressure, and the residue redissolved in DMF $(70 \mathrm{ml})$ and water $(30 \mathrm{ml})$. Another charge of sodium cyanoborohydride $(1.7 \mathrm{~g}, 27.2 \mathrm{mmol})$ was added and the reaction was stirred for 1 hour, at which time the mixture was concentrated to dryness under reduced pressure. The residue was purified by RP-HPLC to give the fluorenylmethyl ester of $\mathrm{N}$-carboxymethyl-D-glucamine (5.75 g 33\%).

A portion of the fluorenylmethyl ester of $\mathrm{N}$ carboxymethyl-D-glucamine $\quad(1.60 \mathrm{~g}, \quad 3.0 \mathrm{mmol})$ was dissolved in DMF $(16 \mathrm{ml})$ and a solution of $\mathrm{NaOH}$ in methanol $(1.0 \mathrm{M}, 6.0 \mathrm{ml}, 6.0 \mathrm{mmol})$ was added. After 40 minutes, the product was precipitated by adding the reaction mixture to $\mathrm{CH}_{3} \mathrm{CN}(90 \mathrm{ml})$. The crude product was isolated by centrifugation and the pellet was washed with $\mathrm{CH}_{3} \mathrm{CN}(90 \mathrm{ml})$. The resulting solid was dried in vacuo to give the sodium salt of $29(0.80 \mathrm{~g}, 99 \%)$.

R- $N$ '-Carboxymethyl-D-glucaminomethyl- $N$-decylaminoethylvancomycin (23)

Amine $29(0.52 \mathrm{~g}, 2.0 \mathrm{mmol})$ and the TFA salt of 2 (790 mg, $0.4 \mathrm{mmol}$ ) were dissolved in $\mathrm{CH}_{3} \mathrm{CN}(3 \mathrm{ml})$ and water $(4 \mathrm{ml})$. DIEA $(0.28 \mathrm{ml}, 1.6 \mathrm{mmol})$ was added, followed by formaldehyde ( $3.7 \%$ aqueous solution, $0.24 \mathrm{ml}$, $0.32 \mathrm{mmol}$ ). The reaction mixture was stirred for 13 hours, at which time HPLC showed that starting material had not been completely consumed. Another portion of formaldehyde was added $(0.10 \mathrm{ml}, 0.13 \mathrm{mmol})$, and the reaction was stirred for 3 hours. The reaction mixture was acidified to $\mathrm{pH} 2$ with TFA and purified by RP-HPLC to give the TFA salt of 23 (147 mg, 16\%).

\section{Determination of In Vitro Antimicrobial Activity}

Minimum inhibitory concentrations (MICs) were determined by broth microdilution methodology as described by the National Committee for Clinical Laboratory Standards ${ }^{22}$.

\section{Single- and Multi-Dose Tissue Distribution Studies}

For the single dose studies, female Sprague-Dawley rats $(\mathrm{n}=3$ per dose group) were dosed at 10 or $50 \mathrm{mg} / \mathrm{kg}$ in $5 \%$ dextrose or $25 \%$ hydroxypropyl- $\beta$-cyclodextrin (HP- $\beta \mathrm{CD}$ ) respectively. For the multiple-dose study, female SpragueDawley rats ( $\mathrm{n}=5$ per dose group) were dosed once daily at $25 \mathrm{mg} / \mathrm{kg}$ in $5 \% \mathrm{HP}-\beta \mathrm{CD}$ for 7 days. Urine samples were cage collected over the 24-hour period following the final dose. Drug concentrations in the urine were determined by LC-MS analysis, and are expressed in the tables as a percentage of a single dose. Twenty-four hours after the last dose, the animals were sacrificed and the liver and kidneys were removed for further analysis. One kidney and part of the liver were homogenized for concentration analysis using reverse phase HPLC with UV detection. The results for liver and kidney distribution given are a percent of the total drug given over the study.

\section{Acknowledgements}

The authors would like to thank Dr. VladimiR Basus (University of California, San Francisco) for NMR spectra and analysis.

\section{References}

1) Neu, H. C.: The crisis in antibiotic resistance. Science 257: 1064 1073, 1992

2) Smith, T. L.; M. L. Pearson, K. R. Wilcox, C. Cruz, M. V. Lancaster, B. Robinson-Dunn, F. C. Tenover, M. J. Zervos, J. D. Band, E. White \& W. R. Jarvis: Emergence of vancomycin resistance in Staphylococcus aureus. Glycopeptide-intermediate Staphylococcus aureus working group. N. Engl. J. Med. 340: 493 501, 1999

3) Sievert, D. M.; M. L. Boulton, G. Stoltman, D. Johnson, M. G. Stobierski, F. P. Downes, P. A. Somsel, J. T. Rudrik, W. Brown, W. Hafeez, T. Lundstrom, E. Flanagan, R. Johnson, J. Mitchell \& S. Chang: Staphylococcus aureus resistant to vancomycin-United States, 2002. Morbid. Mortal. Weekly Rep. 51: 565 567, 2002

4) Diekema, D. J. \& R. N. Jones: Oxazolidinone antibiotics. Lancet 357: 1179, 2001

5) LAMB, H. M.; D. P. FiggitT \& D. Fauds: Quinupristin/Dalfopristin. A review of its use in the management of serious Gram-positive infections. Drugs 58: 1061 1097, 1999

6) Rubenstein, E.; P. Prokocimer \& G.H. Talbot: Safety and tolerability of quinupristin/dalfopristin: administration guidelines. J. Antimicrob. Chemother. 44A: 37 46, 1999

7) Gonzoles, R. D.; P. C. Schreckenbergar, M. B. Graham, S. Kelkar, K. DEbensten \& J. P. Quinn: Infections due to vancomycin-resistant Enterococcus faecium resistant to linezolid. Lancet 357: 1179, 2001

8) LiVermore, D. M.: Quinupristin/dalfopristin and linezolid: where, when, which and whether to use? J. Antimicrob. Chemother. 46: 347 350, 2000

9) Nagarajan, R.; A. A. Schabel, J. L. Occolowitz, F. T. Counter, J. L. OtT \& A. M. Felty-Duckworth: Synthesis and antibacterial activity of $\mathrm{N}$ alkylvancomycins. J. Antibiotics 42: 63 72, 1989

10) Nagarajan, R.: Structure-activity relationships of vancomycin-type glycopeptide antibiotics. J. Antibiotics 46: $1181 \sim 1195,1993$

11) Pavlov, A. Y. \& M. N. Preobrazhenskaya: Chemical 
modification of glycopeptide antibiotics. Russ. Biorg. Chem. 24: 570 587, 1998

12) Pavlov A. Y.; E. I. LazhKo \& M. N. Preobrazhenskaya: A new type of chemical modification of glycopeptide antibiotics: aminomethylated derivatives of eremymomycin and their antibacterial activity. J. Antibiotics 50: 509 513, 1997

13) Judice, J. K.; P. R. Fatheree, B. M. T. Lam, M. R. Leadbetter, M. S. Linsell, S. G. Trapp, G. Yang \& Y. ZHU (Theravance, Inc): Glycopeptide derivatives and pharmaceutical compositions containing the same. U. S. 6,392,012, May 21, 2002

14) Cooper, R. D. G.; N. J. Snyder, M. J. Zweifel, M. A. Staszak, S. C. Wilkie, T. I. Nicas, D. L. Mullen, T. F. Butler, M. J. Rodriguez, B. E. Huff \& R. C. THOMPSON: Reductive alkylation of glycopeptide antibiotics: synthesis and antibacterial activity. J. Antibiotics 49: 575 58, 1996

15) Roberts, G. D.; S. A. Carr, S. Rotterschaefer \& P. W. JEFFS: Structural characterization of glycopeptide antibiotics related to vancomycin by fast atom bombardment mass spectrometry. J. Antibiotics 38: 713 720, 1985

16) Zweifel, M. J.; N. J. Snyder, R. D. G. Cooper, T. I. Nicas, D. L. Mullen, T. F. Butler \& M. J. Rodriguez: Glycopeptide carboxamides active against vancomycinresistant enterococci. J. Antibiotics 56: 289 295, 2003

17) Heck, A. J.; P. J. Bonnici, E. Breukink \& M. Wills:
Modification and inhibition of vancomycin group antibiotics by formaldehyde and acetaldehyde. Chemistry 7: 910 916, 2001

18) Walton, D. J.; E. R. Ison \& W. A. Szarek: Synthesis of $N$-(1-deoxyhexitol-1-yl)amino acids, reference compounds for the nonenzymatic glycosylation of proteins. Carbohydrate Res. 128: 37 49, 1984

19) Leadbetter, M. R. \& M. S. Linsell (Theravance, Inc.): Glycopeptide phosphonate derivatives. U. S. 6,635,618, October 21, 2003

20) Pace, J. L.; K. M. Krause, D. L. Johnston, D. V. Debabov, T. X. Wu, L. Farrington, C. E. Lane, D. L. Higgins, B. G. Christensen, J. K. Judice \& K. Kaniga: In vitro activity of TD-6424 against Staphylococcus aureus. Antimicrob. Agents Chemother. 47: 3602 3604, 2003

21) Hegde, S. S.; N. Reyes, T. Wiens, R. Skinner, J. Mccullough, N. Vanasse \& J. K. Judice: In vitro pharmacodynamics of TD-6424, a novel rapidly bactericidal concentration-dependent antibiotic, in preclinical species. 43rd Interscience Conference of Antimicrob. Agents and Chemother. Chicago, Abstract F2108, 2003

22) National Committee for Clinical Laboratory Standards. Methods for dilution antimicrobial susceptibility tests for bacteria that grow aerobically; approved guideline, 5th ed., M7-A5. The Committee, Wayne, Penn., 2000 